\title{
Layered sulfur / PEDOT:PSS nano composite electrodes for lithium sulfur cell applications
}

\author{
Anilkumar $K M^{a}$, Jinisha $B^{b}$, Manoj $M^{b}$, Pradeep $V S^{b, d}$, S Jayalekshmi ${ }^{b, c}$
}

a) Department of Physics, MSM College, Kayamkulam, Kerala, India

b) Division for Research in Advanced Materials

Department of Physics

Cochin University of Science and Technology

Kochi, Kerala, India 682022

c) Center of Excellence in Advanced Materials

Cochin University of Science and Technology

Kochi, Kerala, India 682022

(d) Laboratory for High Performance Ceramics

Empa

Swiss Federal Laboratories for Materials Science and Technology

Überlandstrasse 1298600 Dübendorf

Switzerland

*Corresponding Address: jayalekshmi@cusat.ac.in

This document is the accepted manuscript version of the following article:

Anilkumar, K. M., Jinisha, B., Manoj, M., Pradeep, V. S., \& Jayalekshmi, S. (2018). Layered sulfur/PEDOT:PSS nano composite electrodes for lithium sulfur cel1 applications. Applied Surface Science, 442, 556-564. http://doi.org/10.1016/j.apsusc.2018.02.178

This manuscript version is made available under the CC-BY-NC-ND 4.0 1icense http: //creativecommons. org/1icenses/by-nc-nd/4.0/ 


\section{Abstract}

Lithium-Sulfur (Li-S) cells are emerging as the next generation energy storage devices owing to their impressive electrochemical properties with high theoretical specific capacity of $1675 \mathrm{mAh} / \mathrm{g}$. Lack of electronic conductivity of sulfur, its volume expansion during high lithium intake and the shuttling effect due to the formation of soluble polysulfides are the main limitations, delaying the commercialization of this technology. To address these challenges, in the present work, the conducting polymer PEDOT: PSS is used as the covering matrix over the sulfur particles to improve their Li storage properties. The sulfur/PEDOT:PSS nanocomposite is synthesised using the hydrothermal process and its formation with the polymer coating over sulfur nanoparticles is established from the XRD, Raman spectroscopy, FE-SEM and TEM studies. The electro-chemical studies show that the cells assembled using the sulfur/PEDOT:PSS nanocomposite as the cathode, with the components taken in the weight ratio of 9:1,offer a reversible capacity of $1191 \mathrm{mAh} / \mathrm{g}$, at 0.1 C rate. These cells display stable electrochemical capacities over 200 cycles at gradually increasing current rates. The polymer layer facilitates electronic conduction and suppresses the polysulfide formation and the volume expansion of sulfur. A reversible capacity of 664 $\mathrm{mAh} / \mathrm{g}$ is observed after 200 cycles at $1 \mathrm{C}$ rate with the capacity retention of $75 \%$ of the initial stable capacity. The highlight of the present work is the possibility to achieve high discharge capacities at high $\mathrm{C}$ rates and the retention of a good percentage of the initial capacity over 200 cycles, for these Li-S cells.

Keywords: Lithium-sulfur cells; conducting polymer; layered nano-composite; rate capability; hydrothermal method. 


\section{Introduction}

Present day research is being focused on identifying suitable materials to make the energy storage technology more efficient, economically viable and scalable for the reach of all sections of the society [1]. Lithium ion based batteries are currently dominating the scenario because of the high energy density in the range of $100-200 \mathrm{Wh} \mathrm{kg}^{-1}$ compared to the various other types of rechargeable cells [2]. To achieve high energy density, high specific capacity and low costs needed for emerging large scale energy storage applications in electric vehicles and space technology, new materials with light weight and multi-electron reactions must be explored. Sulfur being a non-toxic and light weight material, with the added merit of earth abundance has come up as a highly sought after electrode material with a high theoretical capacity of $1675 \mathrm{mAh} \mathrm{g}^{-1}$ and a high energy density of $2600 \mathrm{Wh} \mathrm{kg}^{-1}$ versus lithium, for developing the so called lithium sulfur (Li-S) cells $[3,4]$. The commercialization of Li-S cells is presently facing several challenges owing to low sulfur utilization during cycling, low columbic efficiency and comparatively faster capacity fading [5]. These issues are mainly due to the very poor electrical conductivity of sulfur of the order of $10^{-30} \mathrm{~S} \mathrm{~cm}^{-1}$, the shuttle effect of higher order soluble polysulfides and the large volumetric expansion of sulfur $(\sim 80 \%)$ during the lithiation of sulfur [6] .

The early research in Li-S cells to overcome the above mentioned issues, was focused on the use of carbon based covering matrix over sulfur particles to serve as a conducting as well as a buffering medium. Various carbon materials including porous carbon, carbon black, carbon nanotubes, aerogel carbon, graphene, and carbon composites of graphene and carbon nanotubes have been used as support materials for the sulfur cathode, generally using melt diffusion methods [7-9]. Such processes usually require thermal treatment at elevated temperatures to increase the electronic conductivity of the sulfur - carbon composite. The 
high temperature treatment is often not suitable for sulfur, since it generally results in considerable loss of sulfur in the composite [10]. Recently, the composites of sulphur with conducting polymers have received much attention as prospective cathode materials in Li-S cells. The presence of delocalized $\pi$ electrons in the conducting polymers helps to enhance the electrical conductivity of the composite cathode material $[11,12]$. The electrochemical performance of these types of sulphur-polymer composites will be improved because of the enhanced electrical conductivity, the formation of a buffering polymer matrix to prevent the agglomeration of sulfur and the inhibition of the dissolution of polysulfides in the electrolyte as a consequence of the presence of the polymer coating. There are a number of reports on sulphur-polymer composites based on semiconducting polymers like polypyrrole , polyaniline , polyacrylonitrile , polyimide and poly(3,4-ethylenedioxy thiophene ) poly(styrenesulfonate) (PEDOT:PSS) to serve as the cathode materials in Li-S cells $[13,14]$.

PEDOT:PSS is the most successful conducting polymer in terms of practical applications. The superior conductivity of the order of $10^{3} \mathrm{~S} \mathrm{~cm}^{-1}$ and high work function (5$5.2 \mathrm{eV}$ ) can often induce spontaneous charge transfer with fast kinetics, which endows PEDOT:PSS with catalytic properties. Physically and chemically, PEDOT:PSS possesses good photo and electrical stability in air. Owing to these laudable properties, PEDOT:PSS and PEDOT without PSS doping have found wide applications in energy conversion and storage fields. Generally, PEDOT:PSS finds widespread applications in organic solar cells, dye-sensitized solar cells, electrochemical storage devices, fuel cells, and thermoelectric or stretchable devices $[3,15-23]$. The PEDOT:PSS, is a promising conducting polymer to function as the buffer coating over sulfur, due to its environmental friendliness, good thermal stability and quite high electrical conductivity [24-26]. The polymer is found to retain its high electrical conductivity up to $450 \mathrm{~K}$ [27]. When sulfur is melted at temperatures around $380 \mathrm{~K}$, the PEDOT: PSS coating over the sulfur remains intact and retains its high electrical 
conductivity. The PSS unit in PEDOT:PSS, dispersed in water, helps to form a homogeneous film or layer over sulfur in the composite, as compared to the PEDOT, when used as itself [28].

Studies on cathode materials based on sulfur/ conducting polymer composites have been widely reported with cells offering long-term cycling stability and high reversible capacity. PEDOT coated composite materials are leading the group with reversible capacities in the range of $1100 \mathrm{mAhg}^{-1}$. Li and co-workers have [29] compared the electrochemical performance of different types of sulfur/conducting polymer composites and verified that long-term cycling stability and high discharge capacity are observed for PEDOT coated composite samples. Chen group [13] has reported an initial discharge capacity of $1117 \mathrm{mAh}$ $\mathrm{g}^{-1}$ for S-PEDOT nanocomposite cathode prepared by membrane assisted precipitation technique. Yang group [14] has applied PEDOT based conducting polymer coating on mesoporous sulfur-carbon composite and reported a discharge capacity of $1140 \mathrm{mAh} \mathrm{g}^{-1}$ and a capacity retention of $85 \%$ over 100 cycles. Lee group [30] has applied a wet mixing method (surface modification ) on the commercially available sulfur to prepare S-PEDOT composite and reported an initial discharge capacity of $1100 \mathrm{mAh} \mathrm{g}^{-1}$.

In the present work, we have synthesized sulfur/polymer composite by hydrothermal method using the commercially available sulfur powder and the PEDOT:PSS conducting polymer dispersed in water. The hydrothermal treatment has the advantage of the synthesis of materials at relatively low temperatures to get composites with interesting morphologies and homogenous distribution of the component materials. The hydrothermally synthesized sulfur/polymer nanocomposite can be considered as a potential cathode material for highperformance lithium-sulfur cells, with the advantages of lower energy consumption and short synthesis time with maintenance of high sulfur content in the final composite [10]. In most of the previous reports, the polymer PEDOT as such, without the PSS part has been 
used for making the composite. The advantage of the present approach is that the presence of the PSS part in the water dispersed PEDOT: PSS helps in the formation of layers of the polymer over sulphur particles.

The sulfur/PEDOT:PSS composite cathodes of the present work are evaluated on the basis of the capacity, rate capability, efficiency and cyclability to establish the application prospects of these composite cathode materials in the design of high energy density Li-S cells.

\section{Experimental}

Conductive grade, poly(3,4-ethylenedioxythiophene)- poly(styrenesulfonate), $1.3 \mathrm{wt}$ $\%$ dispersion in $\mathrm{H}_{2} \mathrm{O}$, (PEDOT:PSS), dimethyl sulfoxide ACS reagent, $\geq 99.9 \%$ (DMSO) and sulfur were purchased from Sigma-Aldrich(India) and were used as received.

Three samples with sulfur/PEDOT: PSS ratios of 90:10, 80:20 and 70:30 were synthesized using hydrothermal approach. In a typical preparation, $10 \mathrm{wt} \%$ of PEDOT: PSS was added to $5 \mathrm{ml}$ of dimethyl sulfoxide (DMSO) and left stirring for $4 \mathrm{hrs}$. In a separate beaker, finely powdered sulfur was dispersed in $5 \mathrm{ml}$ of DMSO by stirring for $2 \mathrm{hrs}$. The as prepared PEDOT: PSS in DMSO was then added drop wise to the sulfur dispersion in DMSO and the stirring was continued for another $6 \mathrm{hrs}$. The resulting mixture was transferred to a teflon lined auto clave and kept at a temperature of $120{ }^{\circ} \mathrm{C}$ for $6 \mathrm{hrs}$. The auto clave was allowed to cool to room temperature after the hydrothermal treatment. The resultant product was subjected to washing several times using de-ionized water to remove the residual DMSO. The product obtained after washing was dried at $60{ }^{\circ} \mathrm{C}$ under vacuum overnight to get the final sulfur/PEDOT:PSS composite sample. The sulfur/polymer composite has a greenish appearance and is labelled as PS1. The synthesis procedure is represented in scheme 1 . The above synthesis approach was repeated for compositions with $20 \mathrm{wt} \%$ and $30 \mathrm{wt} \%$ of PEDOT: PSS and the samples obtained are named as PS2 and PS3 respectively. The DMSO 
acts as a surfactant and facilitates the synthesis of the sulfur/PEDOT:PSS composites with particle size in the nanometre scale.

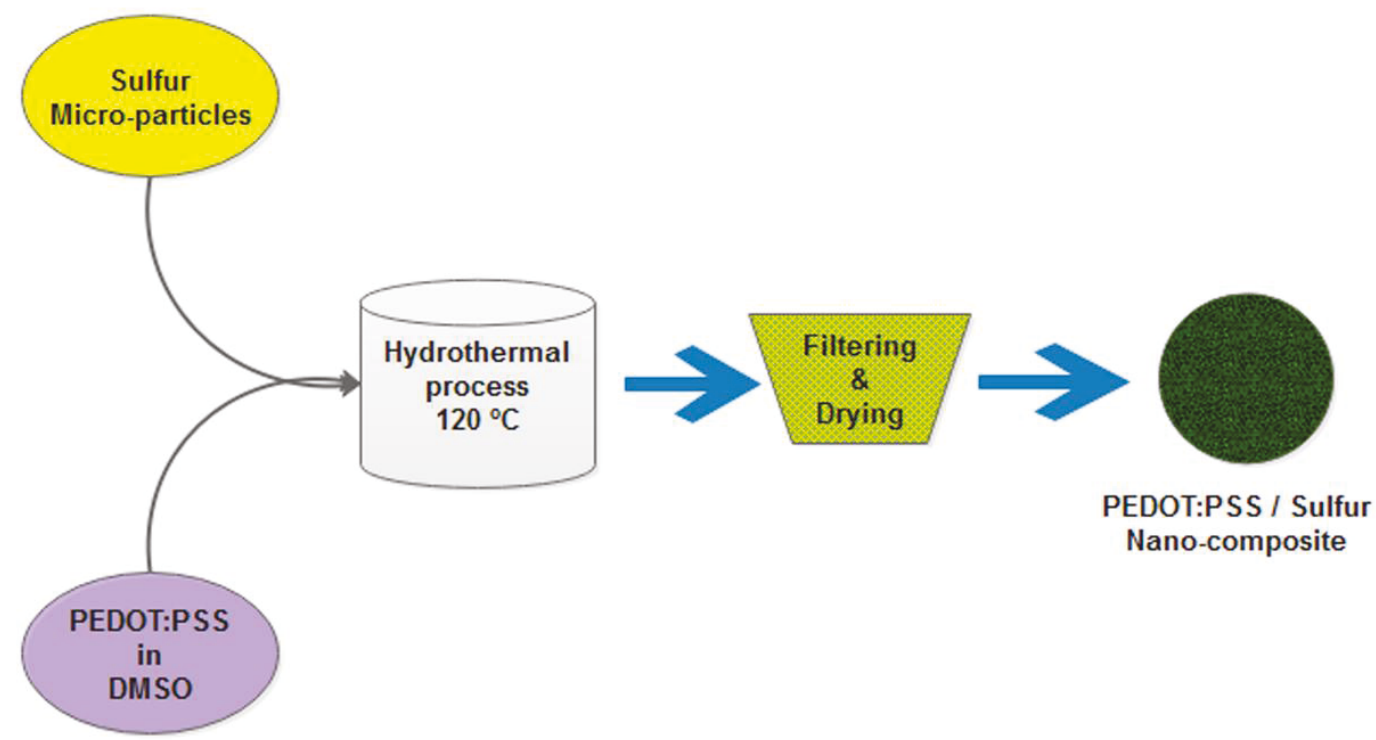

Scheme 1: Schematic representation of the synthesis of sulfur / PEDOT:PSS nanocomposite.

The structural aspects of these samples were studied using XRD technique, employing PANAlytical X'Pert PRO machine with $\mathrm{Cu}-\mathrm{K}_{\alpha}$ radiation of wavelength 1.54Á. Raman studies were carried out using Horiba LabRam $(800 \mathrm{~mm})$ HR spectrometer equipped with a $514 \mathrm{~nm}$ Argon ion laser of $15 \mathrm{~mW}$ power. The morphological aspects of the samples were investigated using Nova Nanosem 450, field emission scanning electron microscope. The high resolution TEM images of the samples were obtained using Jeol/JEM 2100 machine of the Sophisticated Analytical Instrument Facility (SAIF) at CUSAT, Kochi, India. The working electrodes for electrochemical characterisations were prepared by mixing $80 \mathrm{wt} \%$ of sulfur/PEDOT:PSS active material with $10 \mathrm{wt} \%$ of carbon black as conducting medium and $10 \mathrm{wt} \%$ of polyvinylidene difluoride (PVDF) as binder in the presence of $\mathrm{N}$-methyl pyrrolidinone (NMP) solvent. The homogeneous slurry obtained was coated on a thin 
aluminium foil by spray coating and was allowed to dry at $60{ }^{\circ} \mathrm{C}$ under vacuum, overnight. Circular discs of $16 \mathrm{~mm}$ diameter were cut from the coating and used as active cathode electrodes. Electrochemical characterisations were carried out by assembling 2032 type coin cells with $1 \mathrm{M} \mathrm{LiClO}_{4}$ in 1,2-dimethoxymethane (DME)/1,3-dioxolane (DOL) $(1: 1 \mathrm{v} / \mathrm{v})$ with $0.5 \mathrm{M} \mathrm{LiNO}_{3}$ as the electrolyte and lithium chip as the anode [31]. The cells were assembled in an argon filled glove box. The assembled cells were subjected to charge-discharge cycling at current rates of $0.1 \mathrm{C}, 0.2 \mathrm{C}, 0.5 \mathrm{C}$ and $1 \mathrm{C}$ ( The $\mathrm{C}$ rate was calculated, taking the theoretical capacity of sulfur as $1650 \mathrm{mAh} \mathrm{g}^{-1}$ ) within a potential window of $1.5 \mathrm{~V}-3 \mathrm{~V}$ using the 8 Channel Battery Analyser (MTI Corporation-USA). The specific capacity calculations were done with respect to the active sulfur content in the electrodes. The cells were also subjected to cyclic voltammetry (CV) analysis within $1.5 \mathrm{~V}-3 \mathrm{~V}$ at a scanning rate of $0.1 \mathrm{mV} \mathrm{s}^{-1}$. Electrochemical impedance spectroscopic (EIS) measurement of the cells was carried out from $1 \mathrm{MHz}$ to $10 \mathrm{mHz}$ at the open cell voltage of the cells. The electrochemical measurements, CV and EIS were carried out using the Bio-Logic SP300 workstation.

\section{Structural and Morphological Analysis}

\subsection{XRD Analysis}

The XRD patterns of pure sulfur and sulfur/PEDOT: PSS composite samples are shown in Figure 1 . The XRD peaks at $21.77^{\circ}, 23.08^{\circ}, 24.84^{\circ}, 25.71^{\circ}, 26.73^{\circ}, 27.75^{\circ}, 28.78^{\circ}$, $31.3^{\circ}, 34.32^{\circ}, 36.08^{\circ}, 42.94^{\circ}, 47.75^{\circ}$ and $51.12^{\circ}$ are attributed to the $220,222,133,026,311$, $040,117,044,400,244,062,355$ and 535 crystal planes of sulfur respectively. These are the characteristics peaks of the orthorhombic Fddd phase of sulfur observed in the XRD patterns of all the samples studied, which fit well with the JCPDS no. 08-0247 without any impurity phases. Peaks corresponding to PEDOT: PSS polymer are not seen in the XRD patterns owing to its amorphous nature. [30] . A decrease in the intensity of the sulfur diffraction 
peaks is observed with the increase in PEDOT:PSS concentration, which can be attributed to the formation of thicker polymer covering layers over the sulfur particles and the intensity is found to be minimum for the PS3 sample with maximum PEDOT:PSS concentration [32]. The XRD patterns of pure sulfur and sulfur/polymer composites confirm the formation of an active polymer coating over the sulfur particles without any chemical reaction, as the structural features of pure sulfur are found to be retained in the final composite samples.

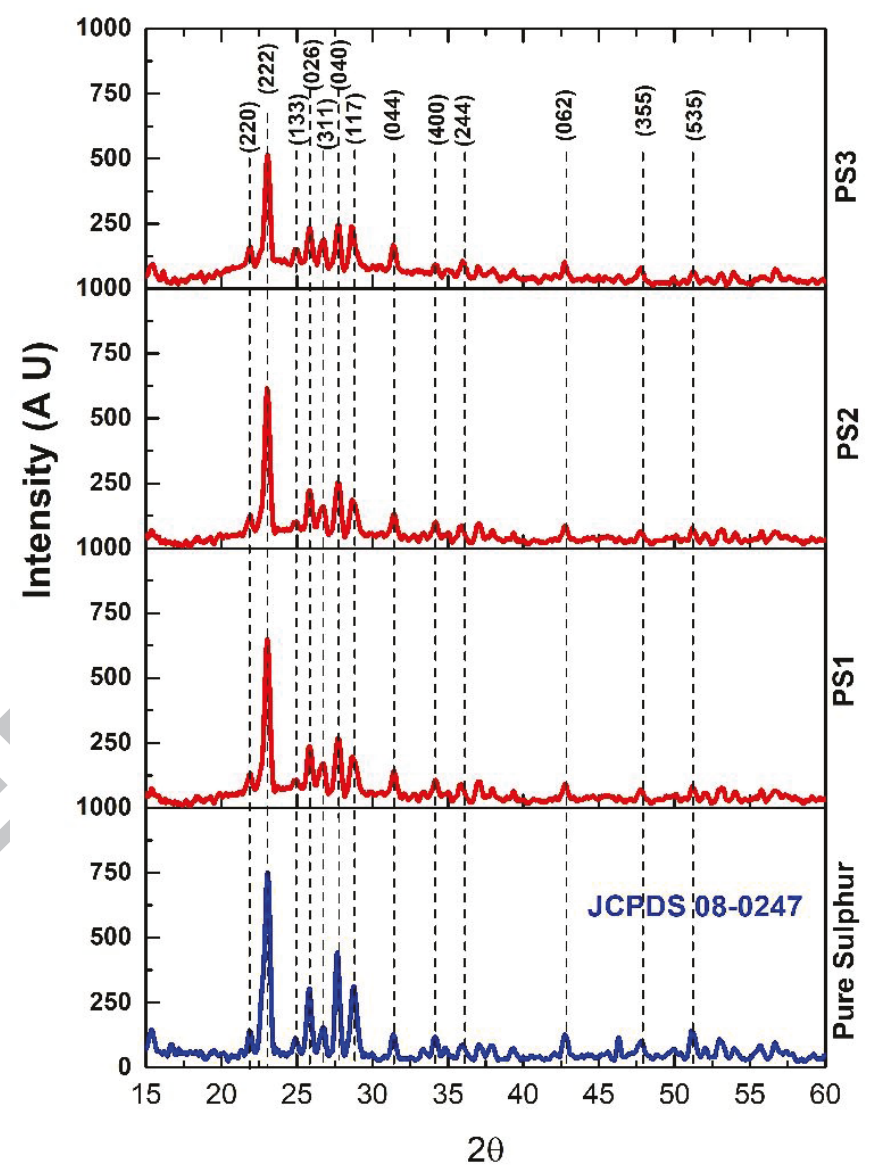

Figure 1: XRD patterns of pure sulfur and PS1, PS2, PS3 composite samples. 


\subsection{Raman analysis}

The Raman spectra of the PS1, PS2 and PS3 composite samples are presented in figures $2 \mathrm{~A}$ and $2 \mathrm{~B}$. The characteristic peaks of elemental sulfur and those of polymer are present in all the studied compositions. The spectra shown in Figure 2A between the range $50-2000 \mathrm{~cm}^{-1}$ have three sharp peaks centred at 153, 220 and $476 \mathrm{~cm}^{-1}$ respectively, which are the signature peaks of elemental orthorhombic sulfur [33]. The peaks of PEDOT: PSS are not visible in figure $2 \mathrm{~A}$. This is either due to the very high intensity of the sulfur peaks or because the resulting coating of the PEDOT: PSS over sulfur is very thin. A separate scan carried out exclusively in the range of $1000-2000 \mathrm{~cm}^{-1}$ is shown in figure $2 \mathrm{~B}$, which clearly gives the characteristic peaks of PEDOT: PSS. The band located at $1264 \mathrm{~cm}^{-1}$ is attributed to the stretching vibration of CR-CR', where R and R' denote alkyl groups [34]. A strong peak at $1442 \mathrm{~cm}^{-1}$ is observed in the Raman spectra. This peak is mainly attributed to the C-C stretching vibration of the thiophene ring, originating from the neutral parts existing between the localized elementary excitations such as positive polarons or bipolarons generated upon doping $[24,22,35,36]$. The peaks centered at $1498 \mathrm{~cm}^{-1}$ and $1570 \mathrm{~cm}^{-1}$ are assigned to the $\mathrm{C}=\mathrm{C}$ asymmetric stretching vibrations of the thiophene rings in the middle and at the end of the chains, respectively [37]. The formation of sulfur/PEDOT: PSS composites through the hydrothermal process with the retention of the individual polymer and sulfur structural features, supports the homogeneous distribution of the sulfur particles in the polymer matrix without any possible chemical reactions between sulfur and the host matrix. The polymer, PEDOT-PSS acts as an ideal support to prevent the aggregation of nanoparticles by dispersing them in its aqueous solution. Also, the content ratio in the composite can be well controlled by varying the content of the sulfur particles. The high pressure formed during the hydrothermal heating in an airtight autoclave is beneficial to obtain molten sulfur at relatively low temperatures. Moreover, the synthesis process in the autoclave prevents any loss of 
sulfur during the hydrothermal heat treatment. These advantageous aspects help the sulfur particles to diffuse into the polymer matrix more homogeneously and rapidly and facilitate the formation of a homogeneous composite.
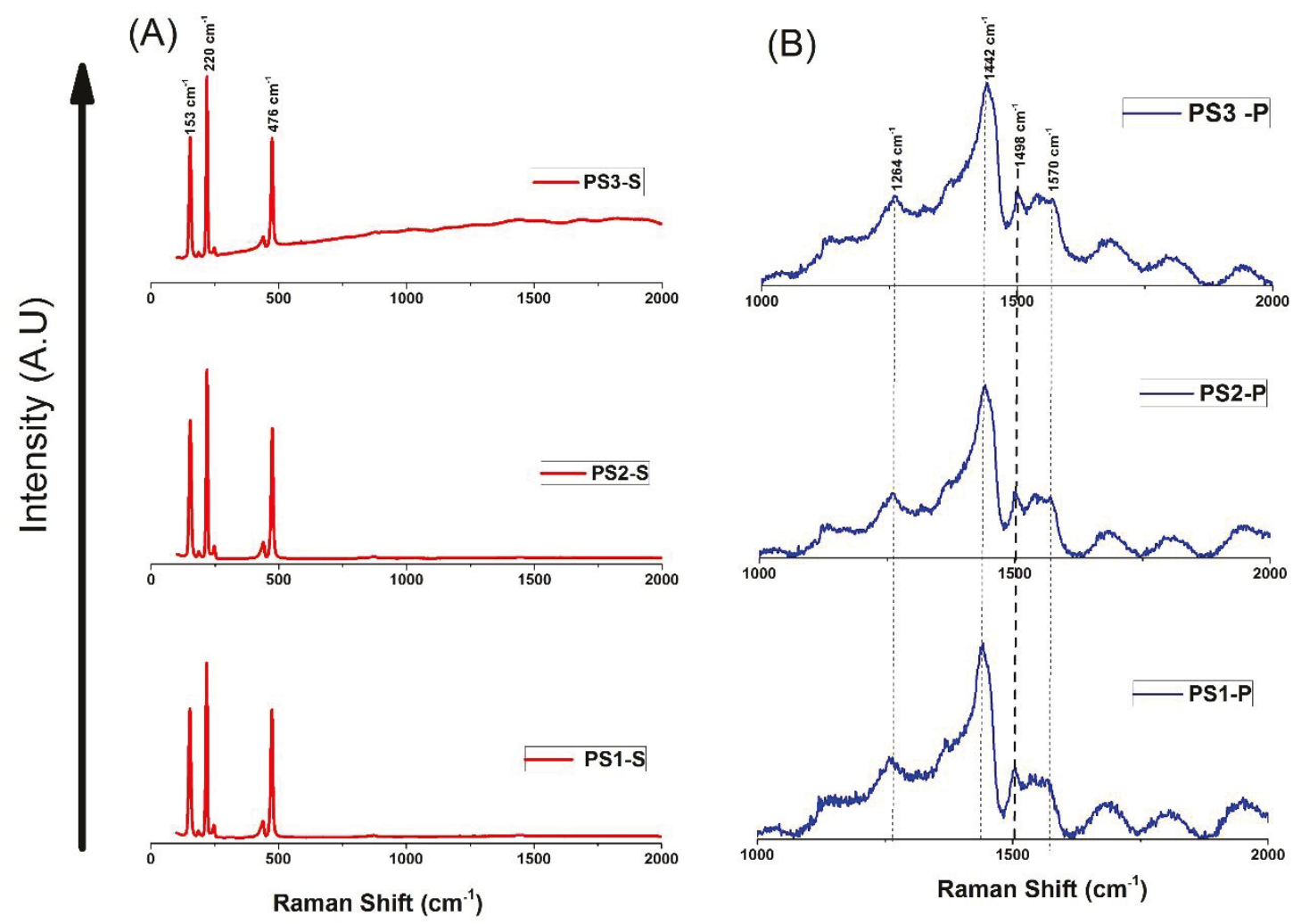

Figure 2: Raman spectra of PS1, PS2 and PS3 samples scanned in the range (A) 50-2000 $\mathrm{cm}^{-1}$ (B) $1000-2000 \mathrm{~cm}^{-1}$

\subsection{FE-SEM and TEM Analysis}

The FESEM images of the studied sulfur/polymer composites are presented in Figure 3, with Figures 3A, 3B and 3C representing individual micrographs of the PS1, PS2 and PS3 compositions respectively. In all the studied compositions, the polymer PEDOT: PSS is expected to form a covering layer over the sulfur particles during the hydrothermal process. The FE-SEM images support the proposed structure of the composites with nano sized sulphur particles embedded within the polymer layers. Increase in the concentration of the polymer in the composite leads to the formation of thicker polymer coating over sulfur 
nanoparticles, which results in partial masking of the active sulfur within the polymer layers. An increased concentration of polymer, results in the formation of more polymer layers over the sulfur particles, which reduces the availability of sulfur during lithium diffusion. This process of masking of the active sulfur particles is evidenced from both the FE-SEM and TEM microscopy results. In the case of PS1 composition, a thin layer of polymer is coated over the particles and the active sulfur is readily visible on the surface of the composite as evidenced from Figure3A. In the images of PS2 and PS3 samples with increased polymer content, sulfur is found to be concealed in between thicker polymer layers with a fewer fraction available on the surface of the composite.

The PS1 sample, with $90 \%$ sulphur content is further subjected to an elemental mapping analysis in order to understand more about the distribution of active sulfur within the polymer layers. In the PS1 sample, active sulfur is seen to be widely distributed all over the composite with the polymer forming only a thin covering layer. Elemental mapping of $\mathrm{C}$, $\mathrm{N}$ and $\mathrm{S}$ contents in the PS1 composite is shown in figure 3D. The mapping confirms the homogeneous distribution of $\mathrm{C}, \mathrm{N}$ and $\mathrm{S}$ elements over the surface of the sulfur/polymer composite. Presence of $\mathrm{C}$ and $\mathrm{N}$ is mainly due to the presence of these elements in the polymer back bone of PEDOT: PSS. Elemental mapping with spots representing sulfur surrounded by those of $\mathrm{C}$ and $\mathrm{N}$, supports the formation of a thin polymer layer over the sulfur particles in the final composite

The TEM image of PS1 composite is shown in figure $3 \mathrm{E}$, which illustrates the presence of nano sized sulfur packed in between thin polymer layers. Sulfur, during the hydrothermal treatment melts and diffuses into the polymer. After the hydrothermal process, polymer forms a thin covering over the sulfur particles, with sulfur being finely distributed in between thin polymer layers. The inset in figure $3 \mathrm{E}$, titled as $3 \mathrm{~F}$ shows the SAED pattern of the PS1 composite with diffused spots representing nano sized sulfur particles and bright 
circles representing the amorphous polymer content. The packing of sulfur in between the polymer layers is further evidenced from figure $3 \mathrm{G}$ with sulfur particles leaking out from the polymer layer. The sulfur particles have nearly spherical shape with particle size in the range of 50-100 nm. Large agglomerates have not been observed in FE- SEM/TEM investigations. The FE-SEM images with elemental mapping, TEM images and SAED pattern clearly confirm the formation of sulfur/PEDOT:PSS nano composite, with the polymer serving as a covering layer over the sulfur particles. 

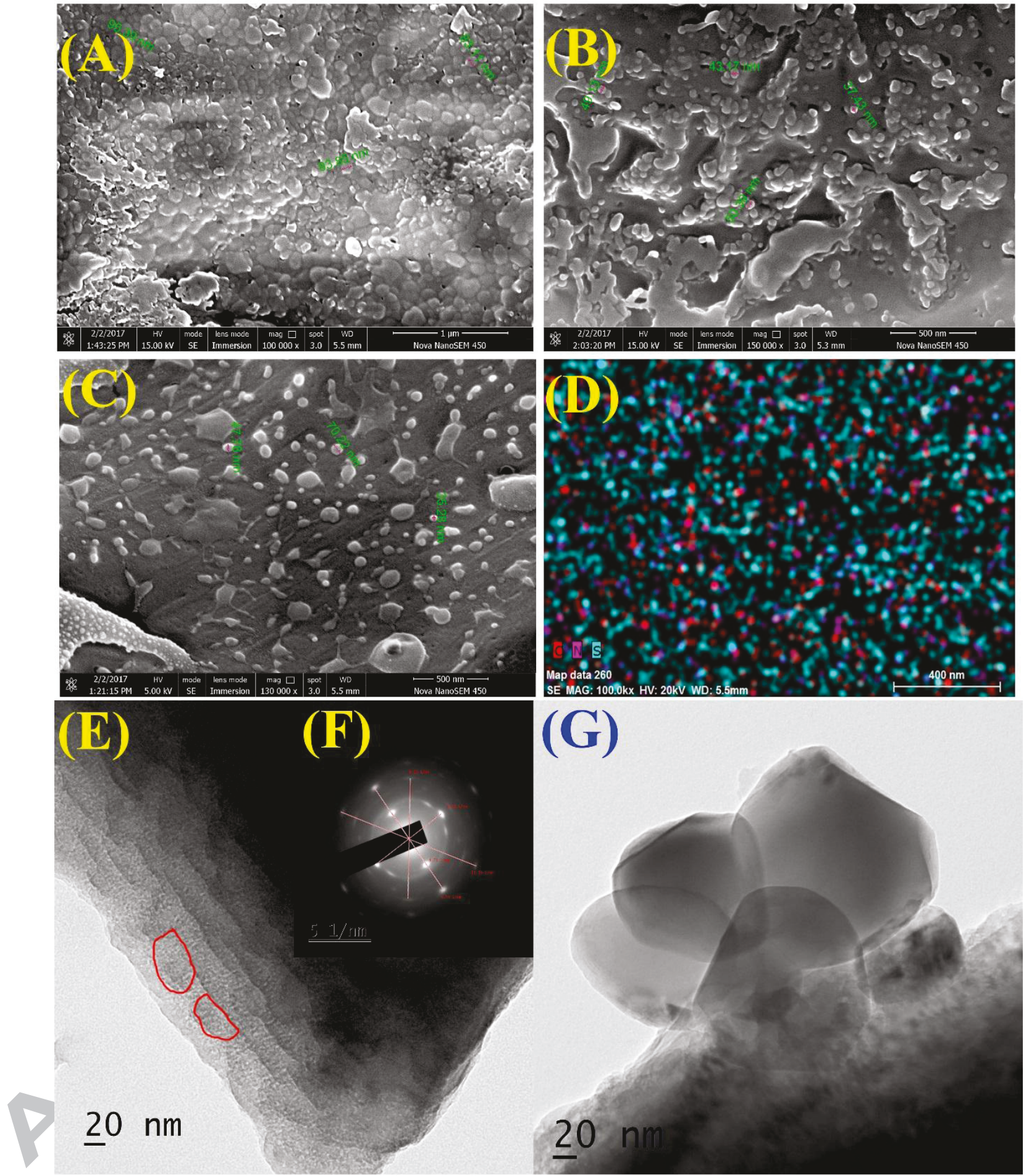

Figure 3: FE-SEM micrographs of (A) PS1 (B) PS2 (C) PS3 samples, (D) Elemental mapping of PS1 sample, (E) and $(G)$ TEM images of PS1 sample and (F) SAED pattern of PS1 sample. 


\section{Electrochemical Studies}

\subsection{Cyclic Voltammetric and Impedance spectroscopic analysis}
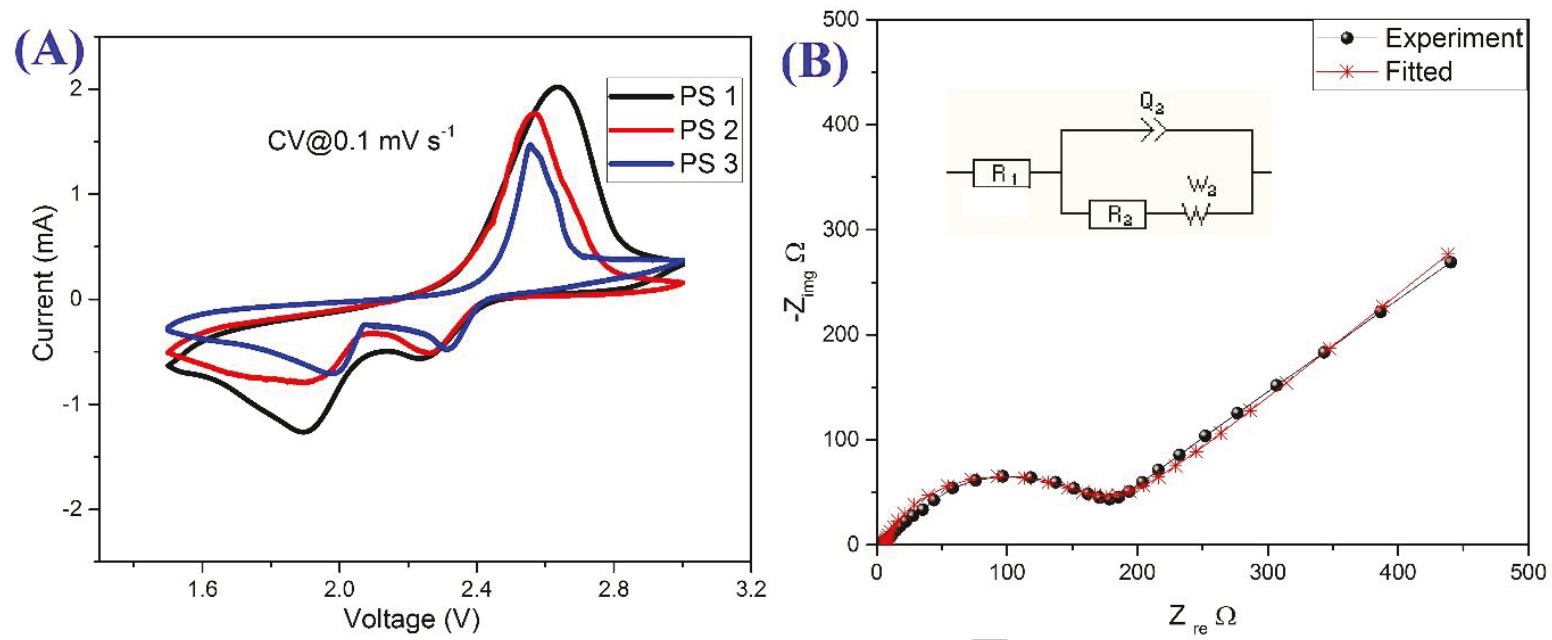

Figure 4: (A) CV curves of PS1, PS2 and PS3 based Li - S cells at a scan rate of $0.1 \mathrm{mV} \mathrm{s}^{-1}$ (B) EIS spectrum of PS1 composite electrode

The cyclic voltammetry curves of the Li-S cells, assembled using the PS1, PS2 and PS3 samples as cathode active materials, between the voltage window of $3 \mathrm{~V}$ to $1.5 \mathrm{~V}$ at a scan rate of $0.1 \mathrm{mV} \mathrm{s}^{-1}$ are shown in figure $4(\mathrm{~A})$. During the first cycle, two broad reduction peaks at $\sim 2.25 \mathrm{~V}$ and $\sim 1.95 \mathrm{~V}$ are observed corresponding to the reduction of elemental sulfur to soluble lithium polysulfides $\left(\mathrm{Li}_{2} \mathrm{~S}_{\mathrm{n}}, 4<\mathrm{n} \leq 8\right)$ and the subsequent formation of insoluble $\mathrm{Li}_{2} \mathrm{~S}$ and $\mathrm{Li}_{2} \mathrm{~S}_{2}$ [5]. The strong and broad oxidation peak observed at $\sim 2.62 \mathrm{~V}$ is due to the conversion of the polysulfides, back to elemental sulfur [12]. For the PS2 and PS3 samples based cells, a small shift in the reduction peaks is observed with respect to those for the PS1 based cell and the peak intensity is also found to be reduced. Similar shift is also observed in the oxidation peaks of PS2 and PS3 based cells, compared to that of the PS1 based cell. Appearance of broader oxidation and reduction peaks for the PS1 based cell indicates the active conversion of soluble polysulfides in to the insoluble forms $\mathrm{Li}_{2} \mathrm{~S}$ or $\mathrm{Li}_{2} \mathrm{~S}_{2}$. Hence for the PS1 based cell, the possibility of sulfur dissolution into the electrolyte can be minimized to a higher degree. Formation of soluble polysulfides with loss of sulfur during multiple 
cycling leads to a reduction in active sites for reversible lithium storage. Up on delithiation, the conversion of the insoluble polysulfides to elemental sulfur takes place more efficiently for the PS1 based cell. The CV results conclusively establish the efficient reversible transitions between $\mathrm{S}_{8}$ and lithium sulfides $\left(\mathrm{Li}_{2} \mathrm{~S}_{2}\right.$ or $\left.\mathrm{Li}_{2} \mathrm{~S}\right)$ in the PS1 based cell, with $90 \%$ of active sulfur present,compared to the other two cells [38] The clear, broad and overlapped $\mathrm{CV}$ peaks in the PS1 based cell also indicate its superior electrochemical activity [14],compared to the PS2 and PS3 based cells.

Maximum electrochemical capacity and cycling stability is observed for the PS1 based cell, with $90 \%$ active sulfur dispersed in $10 \%$ of the remaining conducting polymer layer. The PS1 electrode was further subjected to electrochemical impedance spectroscopy (EIS) studies and the corresponding Nyquist plot is shown in figure 4(B) and the impedance data was fitted with the help of EC-Lab software. The equivalent circuit is shown as inset of Figure 4(B) where, R1 is the resistance of the electrolyte, R2 the charge transfer resistance, Q1 the constant phase element, and W the Warburg diffusion impedance of the electrode. $[39,40]$. The impedance spectrum in Figure 4(B) is composed of one depressed semicircle in the medium-frequency region representing the charge transfer resistance of the interface between the sulphur composite electrode and electrolyte, and the inclined line (Warburg impedance) in the low frequency region, corresponds to the semi-infinite diffusion. The charge transfer resistance is observed to be very low mainly due to the presence of the polymer PEDOT: PSS layer over sulfur, which enhances the overall electrical conductivity of the PS1 composite electrode. This effect, in turn, provides improvement in the electrochemical performance and offers better reversible capacity in Li-S cells. 


\subsection{Charge-Discharge studies}
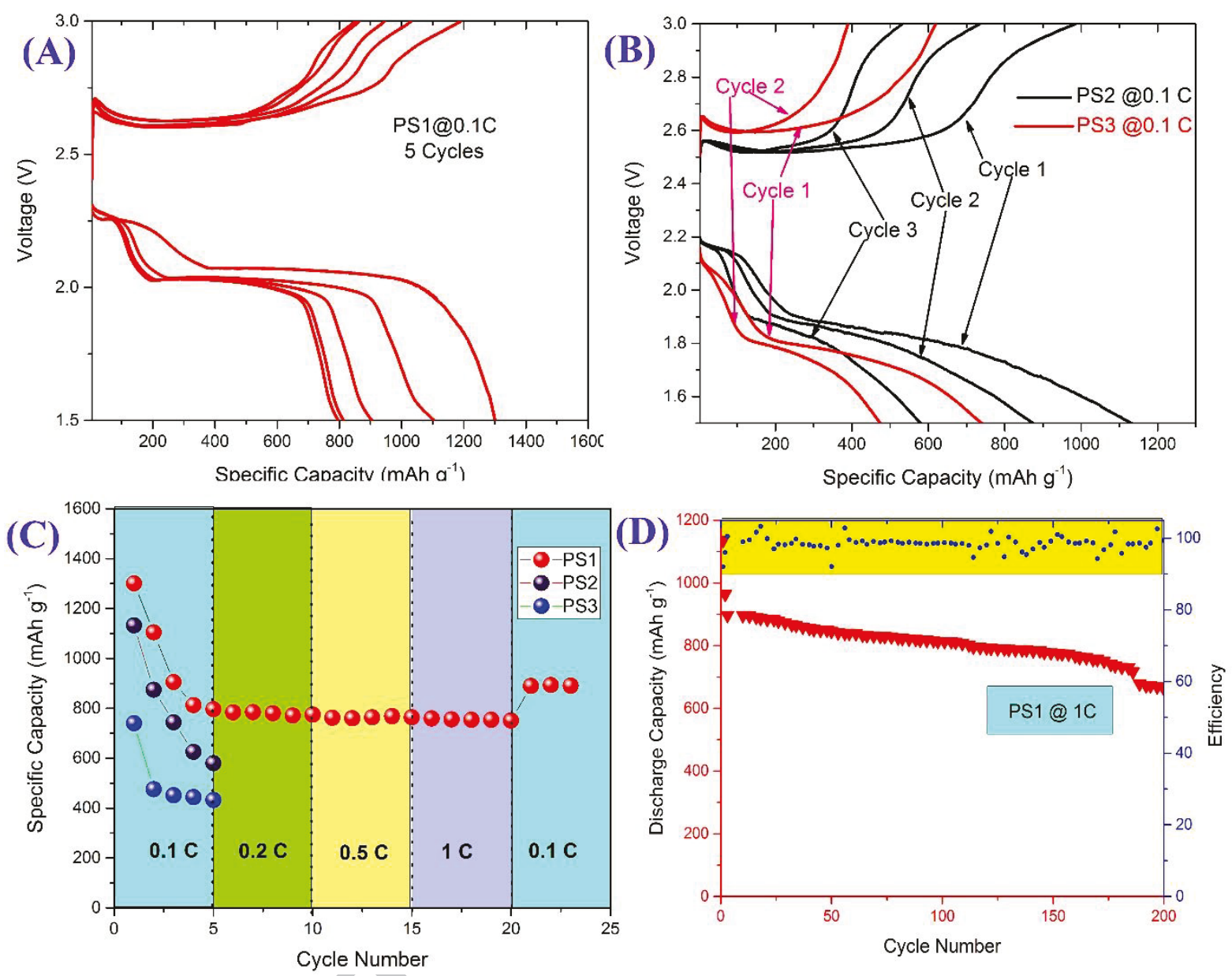

Figure 5: Charge discharge curves of (A) PS1 (B) PS2 and PS3 based Li-S cells (C) Rate capability data of PS1, PS2 and PS3 based cells (D) Cycle life data of the PS1 based cell

The galvanostatic charge-/discharge profiles of the Li-S cells at a rate of $0.1 \mathrm{C}$, assembled using the PS1, PS2 and PS3 composite electrodes are shown in Figures $5 \mathrm{~A}$ and $5 \mathrm{~B}$. The electrochemical charging/discharging capacity and cycling efficiency data are given in table 1. An initial lithiation and delithiation capacities of $1301 \mathrm{mAh} \mathrm{g}^{-1}$ and 1190 $\mathrm{mAh} \mathrm{g}^{-1}$ respectively are observed for the PS1 electrode based cell with a columbic efficiency of $91 \%$. For the PS2 based cell, the lithiation and delithiation capacities are found to be $1132 \mathrm{mAh} \mathrm{g}^{-1}$ and $985 \mathrm{mAh} \mathrm{g}^{-1}$ with $87 \%$ efficiency and for the PS3 based cell, the values are respectively $740 \mathrm{mAh} \mathrm{g}^{-1}$ and $620 \mathrm{mAh} \mathrm{g}^{-1}$ with an efficiency of $83 \%$. The first cycle lithiation profile of the PS1 based cell shows two characteristic plateaus, one at $2.25 \mathrm{~V}$ and 
the other at $2.0 \mathrm{~V}$. The short plateau at $2.25 \mathrm{~V}$ corresponds to the formation of soluble higher order lithium polysulfides, and the longer one, which is observed at $2.0 \mathrm{~V}$ is related to the formation of insoluble lower order lithium polysulfides such as $\mathrm{Li}_{2} \mathrm{~S}_{2}$, and $\mathrm{Li}_{2} \mathrm{~S}$ from $\mathrm{S}_{8}$ during the initial lithiation process within the Li-S cell. The delithiaiton process happens at the potential of $\sim 2.6 \mathrm{~V}$ with the lithium polysulfides, switching back to elemental sulfur.

Table 1: Specific capacity and efficiency data of PS1,PS2 and PS3 based cells

\begin{tabular}{llllll}
\hline & $\mathbf{1}^{\text {st }}$ & & & $\mathbf{3}^{\text {rd }}$ & $\mathbf{5}^{\text {th }}$ \\
\hline $\begin{array}{l}\text { Sample } \\
\text { cells }\end{array}$ & $\begin{array}{l}\text { Discharge } \\
\text { capacity } \\
\left(\mathrm{mAh} \mathrm{g}^{-1}\right)\end{array}$ & $\begin{array}{l}\text { Charge } \\
\text { capacity } \\
\left(\mathrm{mAh} \mathrm{g}^{-1}\right)\end{array}$ & $\begin{array}{l}\text { Efficiency } \\
(\%)\end{array}$ & $\begin{array}{l}\text { Discharge } \\
\text { capacity } \\
\left(\mathrm{mAh} \mathrm{g}^{-1}\right)\end{array}$ & $\begin{array}{l}\text { Discharge } \\
\text { capacity } \\
\left(\mathrm{mAh} \mathrm{g}^{-1}\right)\end{array}$ \\
\hline PS1 & 1301 & 1190 & 91 & 905 & 796 \\
PS2 & 1132 & 985 & 87 & 744 & 580 \\
PS3 & 740 & 620 & 83 & 451 & 432 \\
\hline
\end{tabular}

During the second charge/discharge cycle of the PS1 based cell, a higher columbic efficiency is observed compared to the first cycle, mainly due to a decrease in the formation of higher order polysulfides, as clear from the missing of the plateau at $2.25 \mathrm{~V}$ in the respective charge-discharge profile. Increase in coulombic efficiency also indicates efficient LiSn $\leftrightarrow \mathrm{S}_{8}$ conversion with higher reversibility. For the PS2 based cell, the second cycle lithiation and delithiation capacities get reduced to $874 \mathrm{mAh} \mathrm{g}^{-1}$ and $735 \mathrm{mAh} \mathrm{g}^{-1}$ respectively and for the PS3 based cell, these values are $476 \mathrm{mAh} \mathrm{g}^{-1}$ and $390 \mathrm{mAh} \mathrm{g}^{-1}$ respectively. These capacities are $77 \%$ and $64 \%$ of their respective first cycle capacities. During the $3^{\text {rd }}, 4^{\text {th }}$ and $5^{\text {th }}$ cycles, the discharge capacities of the PS1 based cell are $905 \mathrm{mAh} \mathrm{g}^{-1}, 813 \mathrm{mAh} \mathrm{g}^{-1}$ and $796 \mathrm{mAh} \mathrm{g}^{-1}$ respectively. The capacity attains stability during the $4^{\text {th }}$ and $5^{\text {th }}$ cycles. For the PS2 and PS3 based cells, the retention of capacity is poor with a strong reduction in the reversible electrochemical parameters. Decreased capacities of the PS2 and PS3 based cells could be mainly due to the presence of a thicker polymer coating, which limits the active shuttling of lithium during the charge/discharge process. For these two cells, the main 
lithiation plateau around $2.0 \mathrm{~V}$ is found to be gradually decreasing in its size with cycling, resulting in capacity fading during the cycling process.

The stable capacities of the cell, assembled using PS1 electrode may be attributed to the formation of a thin layer of the polymer coating over sulphur particles, as observed in the FE-SEM and TEM images. The polymer coating is already reported to be beneficial for suppressing the formation of higher order polysulfides. The conducting polymer layer also acts as a buffering medium to control the morphological changes like volume expansion, happening during initial cycling process, in addition to helping in enhancing the overall electrical conductivity of the composite electrode. In the case of the PS2 and PS3 composite based cells, the thicker polymer coatings hinder the easier diffusion of lithium ions to the active sulfur sites. [13].

The cell based on the PS1 electrodes is observed to exhibit much higher capacities compared to the PS2 and PS3 based cells, when cycled at a current rate of $0.1 \mathrm{C}$. The PS1 based cell was further subjected to rate capability studies and the charge/discharge test data of the PS1 based cell at gradually increasing current rates is presented in figure $5 \mathrm{C}$. The capacities are found to be fading during initial cycling and stability is attained after 4 cycles of continuous charge-discharge process. The PS1 based cell is found to deliver a capacity of $796 \mathrm{mAh} \mathrm{g}^{-1}$ at the end of the $5^{\text {th }}$ cycle, with a capacity retention of $\sim 60 \%$ with respect to the first cycle discharge capacity. The cell exhibits a stable behaviour from the $5^{\text {th }}$ cycle onwards up to the $20^{\text {th }}$ cycle, with retention of more or less the same capacity. The cell is also found to retain a capacity of $\sim 751 \mathrm{mAh} \mathrm{g}^{-1}$ at the current rate of $1 \mathrm{C}(1675 \mathrm{~mA} / \mathrm{g})$. It is interesting to note that the cell recovers the initial capacity of $\sim 850 \mathrm{mAh} \mathrm{g}^{-1}$ when cycled at a rate of $\sim 0.1 \mathrm{C}$, after multiple electrochemical cycling at higher current rates. This retention of initial capacity indicates the stability of the PS1 electrode with resistance to any sort of exfoliation during continuous cycling at different current rates. For the PS2 and PS3 based cells, the 
capacities fade very fast from the second cycle onwards and the values drop down to $580 \mathrm{mAh} \mathrm{g}^{-1}$ and $432 \mathrm{mAh} \mathrm{g}^{-1}$, respectively after 5 cycles, and these are much less than their initial capacities. The cell based on the PS1 electrode was also subjected to cycling for 200 cycles at a constant current rate of $1 \mathrm{C}$ to assess the electrochemical cycling stability. The cycling performance and the columbic efficiency values of the PS1 based cell at $1 \mathrm{C}$ rate for 200 cycles are shown in figure 5D. The cell has an initial discharge capacity of $1136 \mathrm{mAh} \mathrm{g}^{-1}$ with $92 \%$ columbic efficiency. The capacity is found to attain a stable value around $897 \mathrm{mAh} \mathrm{g}^{-1}$ with $98 \%$ efficiency at the end of the $3^{\text {rd }}$ cycle. A discharge capacity of $664 \mathrm{mAhg}^{-1}$ is found to be retained at the end of the $200^{\text {th }}$ cycle with the capacity retention of $\sim 75 \%$ with respect to the initial stable capacity.

The improved electrochemical performance of sulfur/polymer composite electrodes can be correlated with the formation of a thin polymer layer around sulfur particles, which acts as a buffering layer to overcome the limitations of the sulfur cathodes. In the present work,the PEDOT: PSS coating improves the electrical conductivity of the sulfur/polymer composite, and this effect, in turn, provides improvement in the electrochemical performance with better reversible capacity in Li-S cells. The improved capacity values of the PS1 electrode based cell can be due to the formation of an efficient, but thin polymer coating on nano sized sulfur particles, with the particles packed in between the polymer layers. The coating helps to prevent the dissolution of polysulfides into the electrolyte, enhances the electrical conductivity of the composite electrode and also acts as a buffer layer to control the volume expansion of sulfur during high lithium intake. Another prime factor, promoting the improved electrochemical performance of the Li-S cells of the present study is the reduced particle size of the sulfur/polymer composite electrode to the nano scale and the size reduction is facilitated by the PEDOT: PSS assisted hydrothermal method of synthesis. The reduced particle size helps to have better contact for the sulfur nano-particles with the 
conducting polymer layer, with the added advantage of having better and easier electron transport across the electrodes and the enhanced utilization of sulfur.

The conducting PEDOT: PSS encapsulation provides better electrical contact and limits the dissolution of lithium polysulfide ions and the shuttling effect during cycling. In addition, the polymer matrix can also prevent the aggregation of sulfur particles. The PEDOT: PSS shells can also accommodate the volume changes associated with the formation of lithium sulfides during the charge/discharge cycles.

\section{Conclusions}

The sulfur / PEDOT: PSS composite electrodes with different weight ratios of the component materials were synthesized by the hydrothermal approach. From the XRD and Raman analysis, the structural integrity of sulfur and PEDOT: PSS in the sulfur/polymer composites can be established. The morphological studies using FE-SEM and TEM techniques confirm the formation of a thin polymer coating over the sulfur particles, with sulfur being finely distributed in between the polymer layers and the particle size reduction of the composites to the nanometre scale, as a consequence of the hydrothermal synthesis in the presence of the surfactant. The presence of the conducting polymer coating over the sulfur particles enhances the overall electrical conductivity of the composite electrode and limits the dissolution of lithium polysulfides and the resulting shuttling effect during cycling. The polymer coating also helps to minimize the volume changes of sulfur due to lithium insertion during the charge/discharge cycles. The electrochemical studies show that the cells assembled using the sulfur/PEDOT: PSS composite, synthesized in 9:1 weight ratio of sulfur and PEDOT: PSS respectively, termed as the PS1 electrode, offer quite impressive electrochemical behaviour with an initial discharge capacity of $1301 \mathrm{mAh} \mathrm{g}^{-1}$ at $0.1 \mathrm{C}$ rate and a columbic efficiency of $91 \%$. The PS1 electrode based cells retain $75 \%$ of the initial stable capacity of $897 \mathrm{mAh} \mathrm{g}^{-1}$ after 200 cycles at a rate of $1 \mathrm{C}$. The electrochemical 
investigations convincingly establish the excellent application prospects of the sulfur/ PEDOT: PSS nanocomposite to be used as the cathode material for developing high energy density, next generation Li-S cells

\section{Acknowledgements}

Anil Kumar K M acknowledges with gratitude the financial support extended by University Grants Commission, Government of India in the form of Teacher Fellowship. Dr. V.S. Pradeep acknowledges the financial support from DST through DST-INSPIRE Faculty award scheme. The authors are grateful to Mrs. Jyothi G, Assistant Professor, Department of Physics, M.S.M College for the help extended to get the FE-SEM images and the Raman spectroscopic data.

\section{References:}

[1] Y.X. Yin, S. Xin, Y.G. Guo, L.J. Wan, Lithium-sulfur batteries: Electrochemistry, materials, and prospects, Angew. Chemie - Int. Ed. 52 (2013) 13186-13200. doi:10.1002/anie. 201304762.

[2] G. Griffiths, Review of developments in lithium secondary battery technology, Underw. Technol. 33 (2016) 153-163. doi:10.3723/ut.33.153.

[3] Q. Pang, X. Liang, C.Y. Kwok, L.F. Nazar, Advances in lithium-sulfur batteries based on multifunctional cathodes and electrolytes, Nat. Energy. 1 (2016) 16132. doi:10.1038/nenergy.2016.132.

[4] A. Manthiram, Y. Fu, Y.-S. Su, Challenges and Prospects of Lithium-Sulfur Batteries, Acc. Chem. Res. 46 (2013) 1125-1134. doi:10.1021/ar300179v.

[5] J.E.S. Technol, X. Zhao, G. Cheruvally, C. Kim, K. Cho, H. Ahn, K. Kim, J. Ahn, Lithium / Sulfur Secondary Batteries : A Review, 7 (2016) 97-114.

[6] K.R. Kim, K.-S. Lee, C.-Y. Ahn, S.-H. Yu, Y.-E. Sung, Discharging a Li-S battery 
with ultra-high sulphur content cathode using a redox mediator, Sci. Rep. 6 (2016) 32433. doi:10.1038/srep32433.

[7] Y.S. Su, Y. Fu, T. Cochell, a Manthiram, A strategic approach to recharging lithiumsulphur batteries for long cycle life, Nat Commun. 4 (2013) 2985. doi:10.1038/ncomms3985.

[8] J. Wu, J. Hu, K. Song, J. Xu, H. Gao, Spirulina-derived nitrogen-doped porous carbon as carbon/S composite cathodes for high cyclability lithium-sulphur batteries, J. Alloys Compd. 704 (2017) 1-6. doi:10.1016/j.jallcom.2017.02.052.

[9] D. Bresser, S. Passerini, B. Scrosati, Recent progress and remaining challenges in sulfur-based lithium secondary batteries - a review, Chem. Commun. 49 (2013) 10545. doi:10.1039/c3ec46131a.

[10] Y. Chen, H. Zhang, X. Yang, K. Feng, X. Li, H. Zhang, A novel facile and fast hydrothermal-assisted method to synthesize sulfur/carbon composites for highperformance lithium-sulfur batteries, RSC Adv. 6 (2016) 81950-81957. doi:10.1039/C6RA19613F.

[11] X. Zhu, Z. Wen, Z. Gu, Z. Lin, Electrochemical characterization and performance improvement of lithium/sulfur polymer batteries, J. Power Sources. 139 (2005) 269273. doi:10.1016/j.jpowsour.2004.07.002.

[12] B.H. Jeon, J.H. Yeon, K.M. Kim, I.J. Chung, Preparation and electrochemical properties of lithium-sulfur polymer batteries, J. Power Sources. 109 (2002) 89-97. doi:10.1016/S0378-7753(02)00050-2.

[13] H. Chen, W. Dong, J. Ge, C. Wang, X. Wu, Ultrafine Sulfur Nanoparticles in Conducting Polymer Shell as Cathode Materials for High Performance Lithium/Sulfur Batteries, Sci. Rep. 3 (2013) 1910. doi:10.1038/srep01910.

[14] Y. Yang, G. Yu, J.J. Cha, H. Wu, M. Vosgueritchian, Y. Yao, Z. Bao, Y. Cui, 
Improving the performance of lithium-sulfur batteries by conductive polymer coating, ACS Nano. 5 (2011) 9187-9193. doi:10.1021/nn203436j.

[15] T. Osaka, Z. Ogumi, Nanoscale Technology for Advanced Lithium Batteries, 2014. doi:10.1007/978-1-4614-8675-6.

[16] D. Zhao, Y. Wang, Y. Zhang, High-Performance Li-ion Batteries and Supercapacitors Based on Prospective Nanomaterials, Nano-Micro Lett. 3 (2011) 62-71. doi:10.5101/nml.v3i1.p62-71.

[17] M. Vangari, T. Pryor, L. Jiang, Supercapacitors: Review of materials and fabrication methods, J. Energy Eng. 139 (2013) 72-79. doi:10.1061/(ASCE)EY.19437897.0000102.

[18] M. Acik, Y.J. Chabal, A Review on Reducing Graphene Oxide for Band Gap Engineering, J. Mater. Sci. Res. 2 (2012). doi:10.5539/jmsr.v2n1p101.

[19] C. Zhong, Y. Deng, W. Hu, J. Qiao, L. Zhang, J. Zhang, A review of electrolyte materials and compositions for electrochemical supercapacitors., Chem. Soc. Rev. 44 (2015) 7484-7539. doi:10.1039/c5cs00303b.

[20] X. Zeng, T. Zhou, C. Leng, Z. Zang, M. Wang, W. Hu, X. Tang, S. Lu, L. Fang, M. Zhou, Performance improvement of perovskite solar cells by employing a CdSe quantum dot/PCBM composite as an electron transport layer, J. Mater. Chem. A. 5 (2017) 17499-17505. doi:10.1039/C7TA00203C.

[21] G.P. Pandey, A.C. Rastogi, C.R. Westgate, All-solid-state supercapacitors with poly(3,4-ethylenedioxythiophene)- coated carbon fiber paper electrodes and ionic liquid gel polymer electrolyte, J. Power Sources. 245 (2014) 857-865. doi:10.1016/j.jpowsour.2013.07.017.

[22] B. Anothumakkool, S.N. Bhange, S.M. Unni, S. Kurungot, 1-Dimensional confinement of porous polyethylenedioxythiophene using carbon nanofibers as a solid 
template: an efficient charge storage material with improved capacitance retention and cycle stability, RSC Adv. 3 (2013) 11877. doi:10.1039/c3ra40853a.

[23] K. Sun, S. Zhang, P. Li, Y. Xia, X. Zhang, D. Du, F.H. Isikgor, J. Ouyang, Review on application of PEDOTs and PEDOT:PSS in energy conversion and storage devices, J. Mater. Sci. Mater. Electron. 26 (2015) 4438-4462. doi:10.1007/s10854-015-2895-5.

[24] T. Ji, L. Tan, X. Hu, Y. Dai, Y. Chen, A comprehensive study of sulfonated carbon materials as conductive composites for polymer solar cells, Phys. Chem. Chem. Phys. 17 (2015) 4137-4145. doi:10.1039/C4CP04965A.

[25] T.-R. Chou, S.-H. Chen, Y.-T. Chiang, Y.-T. Lin, C.-Y. Chao, Highly conductive PEDOT:PSS films by post-treatment with dimethyl sulfoxide for ITO-free liquid crystal display, J. Mater. Chem. C. 3 (2015) 3760-3766. doi:10.1039/C5TC00276A.

[26] E. Vitoratos, S. Sakkopoulos, E. Dalas, N. Paliatsas, D. Karageorgopoulos, F. Petraki, S. Kennou, S.A. Choulis, Thermal degradation mechanisms of PEDOT:PSS, Org. Electron. Physics, Mater. Appl. 10 (2009) 61-66. doi:10.1016/j.orgel.2008.10.008.

[27] E. Vitoratos, Conductivity Degradation Study of PEDOT: PSS Films under Heat Treatment in Helium and Atmospheric Air, Open J. Org. Polym. Mater. 2 (2012) 7-11. doi:10.4236/ojopm.2012.21004.

[28] S.I.W. Gil Ho Kim, Deok Hyun Hwang, Thermoelectric properties of nanocomposite thin films prepared with, Phys. Chem. C Hem. P Hys. (2012) 3530-3536. doi:10.1039/c2cp23517j.

[29] W. Li, G. Zheng, Y. Yang, Z.W. Seh, N. Liu, Y. Cui, High-performance hollow sulfur nanostructured battery cathode through a scalable, room temperature , (2013). doi:10.1073/pnas.1220992110//DCSupplemental.www.pnas.org/cgi/doi/10.1073/pnas.1220992110.

[30] J. Lee, W. Choi, Surface Modification of Sulfur Cathodes with PEDOT:PSS 
Conducting Polymer in Lithium-Sulfur Batteries, J. Electrochem. Soc. 162 (2015) 935-939. doi:10.1149/2.0651506jes.

[31] W. Wang, Y. Wang, Y. Huang, C. Huang, Z. Yu, H. Zhang, A. Wang, K. Yuan, The electrochemical performance of lithium-sulfur batteries with LiClO 4 DOL/DME electrolyte, J. Appl. Electrochem. 40 (2010) 321-325. doi:10.1007/s10800-009-9978$\mathrm{Z}$.

[32] H. Li, M. Sun, T. Zhang, Y. Fang, G. Wang, Improving the performance of PEDOTPSS coated sulfur@activated porous graphene composite cathodes for lithium-sulfur batteries, J. Mater. Chem. A. 2 (2014) 18345-18352. doi:10.1039/C4TA03366C.

[33] B.Y.K. Venkateswarlo, Raman spectrum of sulphur, Proc. Iucl. Acad. Sci., A,. X11, (1940) 453-461.

[34] S. Garreau, G. Louarn, J. Buisson, In situ spectroelectrochemical Raman studies of poly (3, 4-ethylenedioxythiophene)(PEDT), Macromolecules. 32 (1999) 6807. doi:10.1021/ma9905674.

[35] W.W. Chiu, J. Travaš-Sejdić, R.P. Cooney, G.A. Bowmaker, Studies of dopant effects in poly(3,4-ethylenedioxythiophene) using Raman spectroscopy, J. Raman Spectrosc. 37 (2006) 1354-1361. doi:10.1002/jrs. 1545.

[36] M. Reyes-Reyes, I. Cruz-Cruz, R. López-Sandoval, Enhancement of the electrical conductivity in PEDOT: PSS films by the addition of dimethyl sulfate, J. Phys. Chem. C. 114 (2010) 20220-20224. doi:10.1021/jp107386x.

[37] S. Sakamoto, M. Okumura, Z. Zhao, Y. Furukawa, Raman spectral changes of PEDOT-PSS in polymer light-emitting diodes upon operation, Chem. Phys. Lett. 412 (2005) 395-398. doi:10.1016/j.cplett.2005.07.040.

[38] Y. An, P. Wei, M. Fan, D. Chen, H. Chen, Q.J. Ju, G. Tian, K. Shu, Dual-shell hollow polyaniline/sulfur-core/polyaniline composites improving the capacity and cycle 
performance of lithium-sulfur batteries, Appl. Surf. Sci. 375 (2016) 215-222. doi:10.1016/j.apsusc.2016.03.070.

[39] H. Xu, Y. Deng, Z. Shi, Y. Qian, Y. Meng, G. Chen, F. Wei, C.M. Wang, L. V. Saraf, J.G. Zhang, I.A. Aksay, J. Liu, Graphene-encapsulated sulfur (GES) composites with a core-shell structure as superior cathode materials for lithium-sulfur batteries, J. Mater. Chem. A. 1 (2013) 15142. doi:10.1039/c3ta13541a.

[40] L. Yuan, X. Qiu, L. Chen, W. Zhu, New insight into the discharge process of sulfur cathode by electrochemical impedance spectroscopy, J. Power Sources J. 189 (2009) 127-132. doi:10.1016/j.jpowsour.2008.10.033. 


\section{Highlights}

- Sulfur/PEDOT: PSS nanocomposite samples were prepared by hydrothermal method.

- The PEDOT: PSS forms a conducting coating over sulfur nanoparticles.

- The sulfur/PEDOT: PSS composite as cathode show good electrochemical performance.

- Test cells give an initial discharge capacity of $1301 \mathrm{mAh} \mathrm{g}^{-1}$ at $0.1 \mathrm{C}$ rate.

- $75 \%$ of the stable discharge capacity is retained after 200 cycles at $1 \mathrm{C}$ rate 


\section{ACCEPTED MANUSCRIPT}

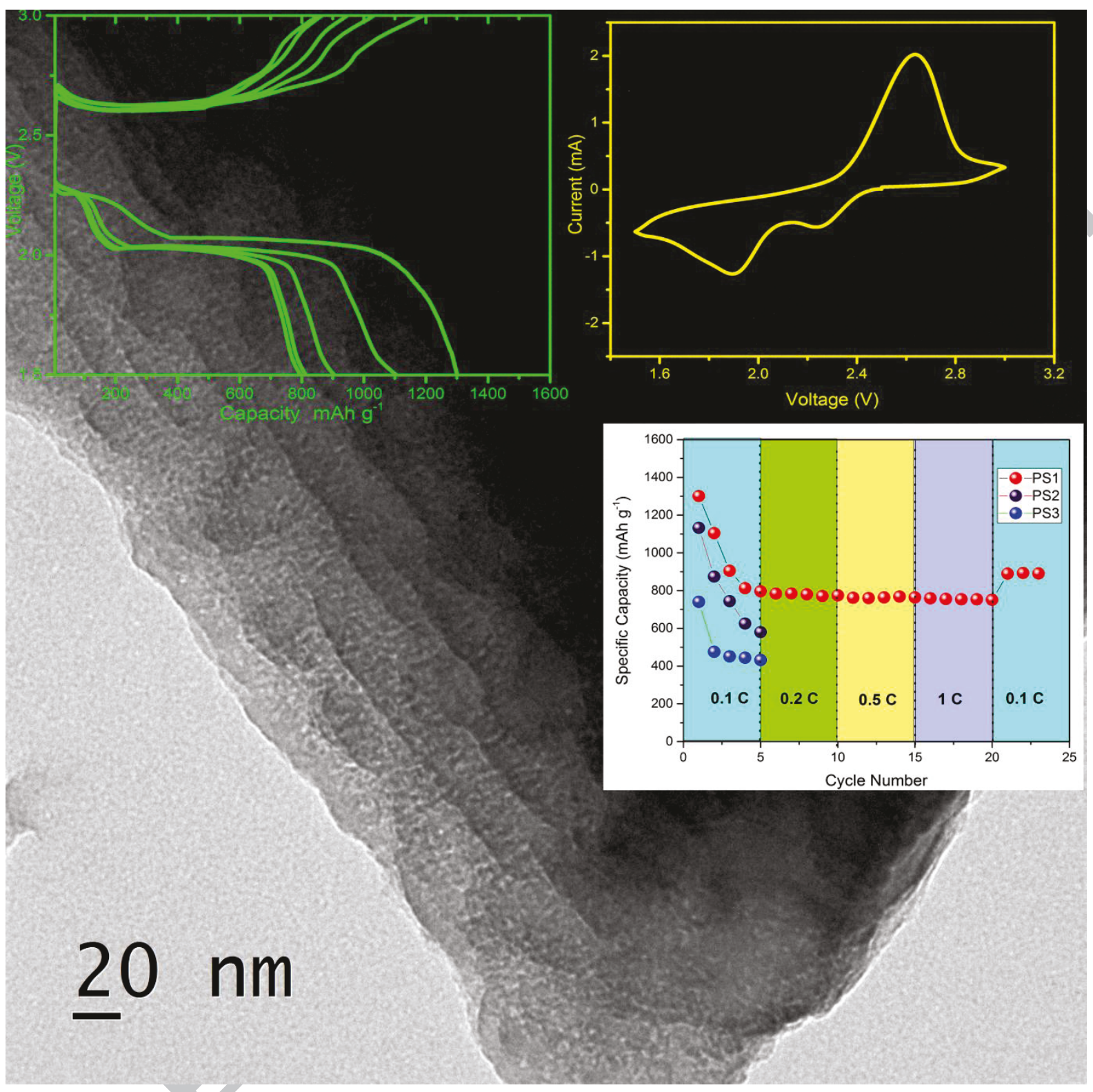

